\title{
LA RESPONSABILIDAD DEL ACREEDOR EN EL REGLAMENTO 655/2014, SOBRE LA ORDEN EUROPEA DE RETENCIÓN DE CUENTAS
}

\author{
CREDITOR'S LIABILITY IN THE REGULATION 655/2014, \\ ON THE EUROPEAN ACCOUNT PRESERVATION ORDER
}

\author{
MARÍA LUISA VILLAMARÍN LÓPEZ \\ Profesora Titular de Derecho Procesal \\ Universidad Complutense de Madrid \\ Instituto de Derecho Europeo e Integración Regional (IDEIR)
}

Recibido: 19.06.2020 / Aceptado: 01.07.2020

DOI: https://doi.org/10.20318/cdt.2020.5679

\begin{abstract}
Resumen: El Reglamento 655/2014, por el que se establece la orden europea de retención de cuentas, ha previsto una serie de mecanismos para equilibrar la posición privilegiada en la que coloca a los acreedores transfronterizos cuando se adoptan este tipo de medidas inaudita parte debitoris. Desde una mirada crítica, este trabajo aborda los dos instrumentos fundamentales que se prevén para este fin: primero, la exigencia de prestación de caución, que constituye presupuesto de este tipo de medidas cautelares en la generalidad de los casos (Art. 12); segundo, el régimen de responsabilidad por culpa del acreedor por los daños y perjuicios irrogados por la adopción de la orden (Art. 13), que se ha previsto como norma de mínimos, dejando casi todos los aspectos de esta responsabilidad a la aplicación de las legislaciones nacionales.

Palabras clave: orden de retención de cuentas, caución, responsabilidad del acreedor, culpa, garantías del deudor.
\end{abstract}

Abstract: Regulation 655/2014, which establishes the European Account Preservation Order, has provided a series of mechanisms to balance the privileged position in which it places cross-border creditors when they request such measure inaudita parte debitoris. In this article, we address critically the two fundamental instruments that are envisaged for this purpose: first, the provision of security, which, as a general rule, is configured as one of the most important requirements of these measures (Art. 12); second, the liability regime due to the creditor for the damages derived from the adoption of the European order (Art. 13), which has been foreseen as a minimum standard and, therefore, has left almost all aspects of this responsibility for the application of national laws.

Keywords: European account preservation order, security, creditors' liability, fault, defendants' guarantees.

Sumario: I. El pretendido equilibrio entre las partes en los procedimientos para acordar las órdenes europeas de retención de cuentas; II. La caución como garantía del deudor en el Reglamento 655/2014: 1. El régimen general de la prestación de caución en el Reglamento 655/2014; 2. La cuan-

\footnotetext{
*Este trabajo fue preparado para ser defendido en el Seminario «Hacia un proceso civil convergente con Europa: balance de situación», dirigido por los Profs. Fernando Gascón Inchausti y Pilar Peiteado Mariscal, que debería haberse celebrado en la Facultad de Derecho de la UCM el 25 de junio de 2020 y que tuvo que ser suspendido como consecuencia de la pandemia asociada al Covid-19. Es uno de los resultados del proyecto de investigación "Hacia un proceso civil convergente con Europa. Hitos presentes y retos futuros" (PGC2018-094693-B-I00), financiado por el Ministerio de Ciencia e Innovación.
} 
tía y forma de la caución; 3. La decisión sobre la caución; 4. Impugnación de la decisión; 5. Excepciones al régimen general de prestación de caución. III. El régimen de responsabilidad del acreedor en el Reglamento 655/2014: I. Introducción; 2. El régimen general de responsabilidad del acreedor; 3. Las presunciones de culpa; 4. La aplicación subsidiaria de las legislaciones nacionales; 5 . La norma de conflicto de leyes; 6. La competencia para conocer de estos asuntos. IV. Consideraciones finales.

\section{El pretendido equilibrio entre las partes en los procedimientos para acordar las órdenes euro- peas de retención de cuentas}

1. El Reglamento 655/2014 (en adelante, ROERC), aprobado el 15 de mayo de 2014, nació con el firme propósito de mejorar y agilizar la retención de activos de las cuentas bancarias en Europa gracias a una pieza clave que marcaba la diferencia respecto de los instrumentos normativos anteriores: la adopción de estas medidas inaudita parte debitoris (Art. 11 ROERC). De este modo, como señalaba su Considerando $15^{\circ}$, "se garantizaba el efecto sorpresa de la orden de retención" y su utilidad para los acreedores que intenten "cobrar sus créditos en asuntos transfronterizos" puesto que el deudor no es informado de la solicitud de esta medida ni se le oye antes de que ésta se acuerde ni tampoco se le notifica su existencia hasta el efectivo cumplimiento de la orden (Art. 28 ROERC). Como puede verse, esta opción legislativa supone una apuesta clara y valiente en pro del éxito de la tutela cautelar instada por los acreedores transfronterizos pero, obviamente, no es gratuita ${ }^{1}$. A nadie se le escapa que el embargo de sus cuentas suele colocar al deudor en una situación de riesgo que se vuelve intolerable cuando la orden se haya acordado sin motivo justificado o sin que concurrieran todos los requisitos procesales exigidos legalmente. Por ello el legislador europeo consideró oportuno establecer ciertas garantías para procurar "un equilibrio adecuado entre el interés del acreedor en obtener la orden y el interés del deudor en evitar que se abuse de esta" (Considerando 14 ${ }^{\circ}$ ROERC). Este trabajo se dedica al análisis de estas garantías con el propósito de verificar si realmente se ha conseguido llegar a ese punto medio o si, por el contrario, la balanza se ha desequilibrado de alguna forma y, en su caso, en qué dirección. En concreto, estudiaremos en detalle las dos medidas adoptadas en el Reglamento con este fin: la primera, la previsión general de caución como presupuesto previo para la adopción de la orden de retención (Art. 12), cuestión a la que se dedica el apartado II de este artículo; y la segunda, el establecimiento de unas normas armonizadoras sobre la responsabilidad que asume el acreedor como consecuencia de la adopción de la medida (Art. 13), que será analizado en el apartado III de este trabajo.

\section{La caución como garantía del deudor en el Reglamento 655/2014}

\section{Régimen general de la prestación de caución en el Reglamento 655/2014}

2. Tal y como ocurre en la regulación de las medidas cautelares en la mayor parte de los ordenamientos nacionales, el Reglamento 655/2014 configura la caución como un presupuesto más para la adopción de la orden de retención, como se desprende del apartado tercero de su Artículo 12: el juez indicará al acreedor que sólo se dictará la orden de retención una vez que se haya prestado la caución de forma adecuada.

3. Ahora bien, cabía la opción de dejar a la discreción del juez su adopción o prever su prestación con carácter obligatorio. Ésta fue una cuestión muy discutida durante su tramitación legislativa. Ini-

\footnotetext{
${ }^{1}$ De hecho, este punto constituía una de las mayores preocupaciones del Reino Unido durante las negociaciones mantenidas para la aprobación de este Reglamento. Así, puede verse, por ejemplo, en el Apartado 16 de la respuestas del Ministerio de Justicia del Reino Unido al texto de la Propuesta: "While many respondents supported the aims of the European Commission's proposal, the majority were concerned that it favours claimants to the detriment of safeguards for defendants" "Mientras que muchos de los que han respondido apoyan los propósitos de la Propuesta de la Comisión Europea, la mayoría están preocupados porque favorece al demandante en detrimento de las garantías de los demandados" -la traducción es nuestra-).
} 
cialmente en la Propuesta de Reglamento se le atribuyó carácter facultativo (Art. 12)릴 lo que dio lugar a importantes críticas por parte de la doctrina ${ }^{3}$ y en sede parlamentaria puesto que se consideraba como una opción poco garantista para la posición de los deudores. Esta tesis fue abandonada en el texto final del Reglamento, en el que se optó por una línea más proteccionista del deudor, consagrando en su Art. 12, como regla general, la obligatoriedad de esta garantía cuando el demandante solicitara la medida sin poseer un título ejecutivo, aunque con ciertas salvedades que se examinarán más adelante ${ }^{4}$. E, incluso, se estableció la posibilidad de poder pedir caución de forma excepcional cuando el acreedor poseyera un título ejecutivo, si así lo aconsejaren las circunstancias del caso (Art. 12.2 ROERC).

\section{La cuantía y forma de la caución}

4. Aunque es el órgano jurisdiccional de origen el encargado de fijar el importe y forma de la caución de acuerdo a sus normas procesales nacionales (Art. 12.3 ROERC), el legislador europeo aclara que su importe ha de ser suficiente para cubrir las dos siguientes finalidades: en primer lugar, ha de procurar evitar que el acreedor abuse del procedimiento; esto es, ha de tratar que con su imposición se impida que el acreedor solicite estas medidas por mala fe para colocar en una situación perjudicial al deudor (por ejemplo, para bloquear su actividad económica, ponerla gravemente en riesgo o malograr su reputación); b) y, segunda, se ha intentar asegurar una cantidad suficiente para garantizar una posible indemnización que podría corresponderle al deudor si se reputara al acreedor responsable de ciertos daños y perjuicios que le hubiere podido causar de acuerdo con el régimen establecido en el Art. 13 del Reglamento, que más adelante estudiaremos. Junto a estos parámetros, el juez deberá aplicar los criterios que prevea su propio sistema procesal, además de seguir los criterios legales y jurisprudenciales europeos; entre ellos destacamos el de proporcionalidad, que, de acuerdo a la lectura que los tribunales europeos han hecho del derecho de acceso a la justicia de los Art. 6 CEDH y $47 \mathrm{CDFU}$, ha de impedir a los tribunales nacionales fijar cuantías procesales excesivas que puedan suponer un obstáculo al demandante para acceder a los tribunales ${ }^{5}$; en este caso, a la tutela cautelar solicitada.

Nada se dice sobre cómo ha de fijarse esta cuantía, si bien la doctrina entiende que el tribunal puede emplear los medios de prueba que entienda oportunos, sin que se aprecie limitación alguna al respecto $^{6}$. Lo que sí que es cierto es que su fijación puede resultar especialmente compleja cuando se hayan de valorar los daños y perjuicios que pudieran llegar a ocasionarse al deudor si, como ocurrirá en muchos de los casos, teniendo en cuenta la aplicación del Art. 13.4 del Reglamento, el régimen de responsabilidad exigible al acreedor se va a regir por la ley del Estado en el que se ejecuta la orden (llamado Estado de ejecución) y, por tanto, será derecho extranjero para el juez que tiene la tarea de fijar la cuantía de la caución. Aunque no será lo deseable, el Considerando $18^{\circ}$ ROERC señala que, si en estos casos no hay "pruebas específicas sobre la cuantía de los daños y perjuicios potenciales", el juez debe tener potestad para "considerar orientativo el importe por el que vaya a dictarse la orden a efectos de

\footnotetext{
${ }^{2}$ Señalaba así el texto: “antes de dictar la OERC, el órgano jurisdiccional podrá exigir que el demandante aporte depósito de garantía o una fianza equivalente para cubrir la indemnización por cualquier daño que pueda sufrir el demandando (...)".

${ }^{3}$ Ver entre otros, DomEJ, T., "Die geplante Verordnung über die Europäische vorläufige Kontenpfändung”, ZEuP, 2013 , p. 501.

${ }^{4}$ Así, se establece el verbo "requerirá" (en sentido idéntico en otras versiones: en inglés: "shall require"; en alemán: "verlangt"; en francés, "exige"; en italiano: "impone"). De este carácter obligatorio ya se hacía eco el texto del Dictamen del Comité Económico y Social Europeo de 26 de abril de 2012.

${ }^{5}$ Véase sobre esta cuestión, Villamarín López, M.L., en Díez - Picazo Giménez, I., y Vegas Torres, J. (coord.), Derecho, Justicia, Universidad (Liber Amicorum de Andrés de la Oliva Santos), Ed. CERA, 2016, p. 3237: El Tribunal Europeo de Derechos Humanos entiende que su finalidad es "compatible con la recta administración de justicia" (Asunto Harrison Mckee v. Hungría, de 3 de junio de 2014, núm. 22840/07) y que, al menos en parte, "sirven como medida que disuade a potenciales litigantes de plantear peticiones irrazonables y faltas de fundamento" (Asunto Gaile v. Latvia, de 26 de noviembre de 2013, núm. 48590/07). Ahora bien, lo que se debe controlar es, por un lado, que no sean excesivas y supongan una carga. Así, por ejemplo, en el Asunto Kijewska v. Polonia, de 6 de septiembre de 2007 (núm. 73002/01), en el que la tasa cuadriplicaba el salario mínimo interprofesional. También se consideraron excesivas en los Asuntos Kreuz v. Polonia, de 19 de junio de 2001, núm. 28249/95; Jedamsky y Jedamska v. Polonia, de 26 de julio de 2005, núm. 73547/01; Weissman y otros v. Rumanía, de 4 de junio de 2006.

${ }^{6}$ Vid. Hilbig-Lugani, K., en Münchener Kommentar, Ed. Beck, 2017, Art. 12.
} 
determinar la cuantía de la caución". Al importe resultante de la valoración judicial, considera parte de la doctrina alemana, que se le debería sumar un diez por ciento en concepto, por ejemplo, de intereses y de costas procesales ${ }^{7}$.

5. En cuanto a la forma que ha de adoptar la caución, el Reglamento también se remite a la normativa nacional ${ }^{8}$. Únicamente a modo de ejemplo, el Considerando $18^{\circ}$ señala que podrá prestarse en forma de "fianza u de otro tipo de garantía, como una garantía bancaria o una hipoteca".

\section{La decisión sobre la caución}

6. Teniendo todo esto en cuenta, el tribunal decidirá sobre la caución en los plazos y en la forma prevista por el Reglamento.

7. En cuanto a los plazos, el apartado cuarto del Art. 18 ROERC establece que será de aplicación lo previsto en los apartados primero a tercero de ese mismo precepto para definir los tiempos en los que el acreedor debe prestar caución. En consecuencia, habrá que adecuarse a las siguientes reglas:

a) En el caso de que el acreedor ya poseyera un título ejecutivo, deberá acordar la caución "a más tardar a los diez días hábiles desde que el acreedor haya presentado o, en su caso, completado su solicitud", plazo bastante breve para esta tarea de fijación de la caución si se tiene en cuenta las posibles actividades que debe llevar a cabo el juez para poder realizar una oportuna valoración de las circunstancias del caso;

b) si el acreedor no tuviera título, se deberá decidir sobre la prestación de esta garantía "a más tardar en los cinco días hábiles desde que el acreedor haya presentado o, en su caso, haya completado su solicitud";

c) por último, si el órgano judicial considerare necesaria la celebración de una audiencia oral del acreedor y, en su caso, de sus testigos, la convocará "sin demora" y dictará la resolución "a más tardar a los cinco días hábiles desde la fecha de la audiencia".

Nada se dice sobre el plazo en el que el acreedor debe prestar la caución, que entendemos que el juez deberá fijar discrecionalmente en su decisión, atendiendo a su normativa nacional.

Desde el momento en que se presta la caución por el acreedor, el órgano jurisdiccional debe dictar la orden "sin demora" (Art. 18.4 ROERC).

8. Por lo que respecta a su contenido, el Art. 12.3 ROERC únicamente exige que se indique su importe, la forma que haya de adoptar y su condición de presupuesto de la orden de retención, sin que expresamente el Reglamento requiera motivación. Con todo, es fácil que ésta sea exigible por las legislaciones nacionales para facilitar su posible impugnación (Art. 33.2 ROERC); de hecho, así se prevé en el formulario oficial de la orden de retención (Apartado $9^{\circ}$ del Anexo I del Reglamento de Ejecución 2016/1823 de la Comisión).

\section{Impugnación de la decisión}

9. La decisión sobre la caución es clave para garantizar el equilibrio entre los intereses de acreedores y deudores y, por ello, ha de adoptarse con la mayor cautela para que no se malogre el éxito de la pretensión del acreedor si la cuantía resulta demasiado elevada ni se exponga innecesariamente al

\footnotetext{
${ }^{7}$ Cfr. Schlosser, P. y Hess, B., en EU Zivilprozessrecht, Ed. Beck, 2015, p. 448; Hilbig-Lugani, K., en Münchener Kommentar, op.cit., Art. 12.

${ }^{8}$ Por ejemplo, en España las modalidades que puede adoptar la caución están previstas en el Art. 529.3 LEC; en Alemania, en el parágrafo 108 ZPO; en Polonia, en el parágrafo 746 ZVGB; en Austria, en el parágrafo 562 ZPO.
} 
deudor a situaciones de riesgo si fuere muy baja. En cualquier caso, parece que es muy relevante para garantizar su adecuación que ambas partes cuenten con herramientas para impugnar estas decisiones si no están conformes con su contenido y alcance.

10. Es claro que el Reglamento ofrece al deudor la posibilidad de atacar la decisión sobre la caución con arreglo al Art. 33.2 ROERC: "se reexaminará la decisión relativa a la caución prevista en el Art. 12 en caso de que no reúnan las condiciones o requisitos previsto en dicho artículo". Por tanto, el deudor podrá cuestionar tanto la decisión de no imponer la caución, rebatiendo las circunstancias que justificaron tal decisión, como su importe, si considera que el fijado por el tribunal puede resultar insuficiente para cubrir posibles daños y perjuicios. Aunque nada se dice en dicho precepto, es claro que podrá practicarse prueba sobre los extremos en los que el deudor apoye sus alegaciones. En caso de que el tribunal estime sus pretensiones, se exigirá al acreedor la prestación de la caución controvertida o de una caución adicional en las mismas condiciones fijadas por el Art. 12.3 ROERC, advirtiéndole de que, "en caso de que no preste la garantía (adicional) exigida en el plazo establecido por él", podrá revocar o modificar la orden (Art. 33.2.2 ROERC).

11. No gozan, sin embargo, de análoga protección los acreedores, ya que el Reglamento no prevé expresamente ningún mecanismo de impugnación frente a la decisión que acuerda la caución, pese al interés que los demandantes puede tener si consideran que el importe por el que se ha acordado carece de justificación suficiente o resulta desproporcionado. Claro está que podrán hacer uso de los recursos que prevean los Derechos nacionales frente a este tipo de decisiones, de acuerdo a lo dispuesto en el Art. 46.1 ROERC ${ }^{9}$, precepto en el que se establece la aplicación de las normas internas para todas las cuestiones procesales sobre las que no se pronuncie el Reglamento. Pero esta situación puede crear diferencias importantes entre los Estados miembros en función de si contemplan o no mecanismos de impugnación en su ordenamiento interno. Aunque no es una solución óptima porque no supondría una impugnación directa frente a la decisión que resuelve sobre la caución ${ }^{10}$, consideramos que sería razonable aplicar lo dispuesto en el Art. 21 ROERC para la impugnación de las decisiones denegatorias de la orden.

\section{Excepciones al régimen general de prestación de caución}

12. Como ya se comentó anteriormente, aunque el Reglamento opta por generalizar la caución en los supuestos en los que el acreedor no tiene en su poder un título ejecutivo, ya que en ese momento es posible afectar de forma más perjudicial o injustificada la posición del deudor, esta exigencia de caución no es absoluta ni siquiera en estos casos. Como señala el Art. 12.1.II ROERC, esta regla podrá salvarse "excepcionalmente" si el juez "considera que la prestación de una caución a que se refiere dicho párrafo es improcedente dadas las circunstancias del caso". Deberá, por tanto, evaluarse caso por caso si se dan o no las circunstancias que justifiquen dicha exención. Aunque la versión española del Art. 12.1.II ROERC emplea el término "improcedente", creemos más ajustado al espíritu de la norma el uso de la expresión "inapropiado", utilizado en otras versiones ${ }^{11}$, ya que en la mayor parte de los casos sí que procedería conforme a derecho la prestación de caución pero se considera más oportuno no exigirla por las razones que aprecie en el caso el tribunal. De hecho, en este sentido apunta el Considerando 18.II ${ }^{\circ}$ ROERC cuando señala que "el órgano jurisdiccional debe eximir de esta obligación o requerir una caución por un importe inferior si considera que dicha caución es improcedente ("inadecuada" en los otros idiomas), superflua o desproporcionada dadas las circunstancias concretas del caso", señalando a continuación ejemplos de dos

\footnotetext{
${ }^{9}$ Cfr. Hilbig-Lugani, K., en Münchener Kommentar, op.cit., Art. 12.

${ }^{10}$ Es más, a diferencia del detalle con el que precisa el contenido de la decisión de estimación, ni en el Reglamento ni los formularios que lo desarrollan prevén nada sobre el contenido y forma de las resoluciones de desestimación o denegación de la orden, por lo que, cuando no se presta caución en tiempo y forma, no queda claro si se dicta una resolución (desestimatoria) o si simplemente no se acuerda la orden sin que haya una decisión judicial que la contenga.

${ }^{11}$ En la versión inglesa "innappropriate"; en la francesa, "inappropieé"; en la italiana "innoportuna"; en la alemana, "unangemessen".
} 
de estas tres situaciones. Inadecuada sería cuando, pese a que su pretensión está bien fundada, "no tiene medios suficientes para prestar una caución" o si el "crédito se deriva de una obligación de alimentos o del pago de sueldos o salarios" (o, igualmente, aunque no lo señala el Reglamento, si se tratara de consumidores o de materia de seguros, objeto de especial protección en el Reglamento de Bruselas Ibis). Superflua si "la cuantía del crédito es tal que no es probable que la orden cause daño o perjuicio al deudor".

Para poder conseguir que el juez aprecie esta exención, el Reglamento prevé expresamente la posibilidad de que el acreedor alegue en su solicitud toda la información relevante al respecto (Art. 8.2.k y 1 y formulario de la ROERC). Con todo, coincidimos con quienes defienden que el tribunal podría también apreciar de oficio estas circunstancias excepcionales (en especial, en el caso de que se trate de los sectores más débiles como los consumidores), máxime dado que no se exige la presencia de abogados para asistir a las partes para la solicitud de estas medidas en el marco de este procedimiento europeo ${ }^{12}$.

14. También se presentan excepciones en los supuestos en los que el acreedor goza de título ejecutivo cuando insta la adopción de esta medida. Pese a que el criterio general en estos casos es el de no prestación de caución, puesto que ya no es previsible que el procedimiento produzca daños improcedentes al deudor, sin embargo, en algunos casos pueden existir aún ciertos riesgos que pueden precaverse con la prestación de caución. Así, en estos supuestos se deja a discreción del tribunal poder exigirla "si lo considera necesario y adecuada dadas las circunstancias del caso" (Art. 12.2 ROERC). En concreto, el Considerando $18^{\circ}$ ROERC entiende que esto puede ocurrir, por ejemplo, "cuando la resolución cuya ejecución se pretende asegurar por medio de la orden de retención no sea ejecutiva o solo sea ejecutiva provisionalmente debido a que haya un recurso pendiente".

\section{El régimen de responsabilidad del acreedor en el Reglamento 655/2014}

\section{Introducción}

15. Inicialmente, en la Propuesta de Reglamento ${ }^{13}$, no se preveía ninguna norma que unificara a nivel europeo la cuestión de la responsabilidad del acreedor, sino que simplemente se hacía una remisión a las legislaciones nacionales. Así, en el mismo artículo que se ocupaba de la caución, se señalaba: "Antes de dictar la OERC, el órgano jurisdiccional podrá exigir que el demandante aporte un depósito de garantía o una fianza equivalente para cubrir la indemnización por cualquier daño que pueda sufrir el demandado en la medida en que el demandante esté obligado a indemnizar tales daños conforme a la legislación nacional" (Art. 12) ${ }^{14}$.

Pero durante la tramitación legislativa del Reglamento 655/2014 se advirtió la enorme dificultad que suponía la aplicación de normas muy diversas de responsabilidad por daños (diferencias en los

${ }^{12}$ Cfr. Cuniberti, G. y Migliorini, S., The European Account Preservation Order Regulation, Ed. Cambridge University Press, 2018, p. 163. En contra, SANDRINI, L., "La procedura "per l'adozione” dell'ordinanza europea di sequestro conservativo dei conti bancari”, en Il sequestro conservativo di conti bancari, Ed. Giuffrè, Milán, 2015, en p. 69.

${ }^{13}$ Propuesta de REGLAMENTO DEL PARLAMENTO EUROPEO Y DEL CONSEJO por el que se crea la orden europea de retención de cuentas para simplificar el cobro transfronterizo de deudas en materia civil y mercantil/* COM/2011/0445 final - 2011/0204 (COD) */. Véase en: https://eur-lex.europa.eu/legal-content/ES/TXT/?uri=CELEX\%3A52011PC0445.

${ }^{14}$ En un sentido algo más completo, se señalaba en el Proyecto de Resolución del Parlamento Europeo sobre el texto de la Comisión que: (15) "El presente Reglamento debe ofrecer garantías suficientes contra el abuso de la orden. En particular, salvo que el acreedor ya disponga de una resolución judicial con fuerza ejecutiva en el Estado miembro de ejecución, el órgano jurisdiccional debe exigirle que aporte una garantía para la indemnización por cualquier daño que sufra el deudor como consecuencia de una orden injustificada o de que no se liberen, en los plazos previstos, fondos por un importe superior al establecido en la orden. (15 bis) El presente Reglamento debe prever la responsabilidad legal del demandante con respecto al demandado por los posibles daños causados a este último como consecuencia de una orden posteriormente considerada injustificada. La indemnización por dichos daños deberá incluir, como mínimo, las pérdidas de ingresos y los costes incurridos durante el proceso. Además, es conveniente que el demandante sea asimismo responsable de los posibles daños causados al demandado cuando no se liberan rápidamente fondos por un importe superior al indicado en la orden". 
tipos de responsabilidad ${ }^{15}$, en el concepto de culpa, en el alcance de los daños y perjuicios que pueden ampararse, en las reglas de carga de la prueba o en la existencia de presunciones de distinta naturaleza) $\mathrm{y}$, en consecuencia, se decidió dar un paso más y armonizar esta cuestión, dándole un tratamiento independiente en un nuevo artículo titulado "Responsabilidad del acreedor" (Art. 13).

16. Tres cuestiones conviene adelantar antes de analizar en detalle este precepto.

1) Primera, que la opción legislativa no ha sido muy arriesgada puesto que el contenido de este precepto es muy escueto y, sobre todo, porque, como adelanta el Considerando $19^{\mathrm{a}}$ ROERC, constituye una regla de mínimos: "el presente Reglamento debe establecer, como mínimo, la responsabilidad del acreedor cuando el daño o perjuicio ocasionado al deudor por la orden de retención se deba a su culpa" (que se regula en el apartado primero del Art. 13 ROERC). Por tanto, se ha previsto una regla general de responsabilidad por culpa en este primer párrafo, completada por una presunción de culpabilidad que se aplica para cuatro supuestos tasados en los que los daños derivan del incumplimiento del acreedor de ciertas exigencias u obligaciones impuestas por el Reglamento (apartado $2^{\circ}$ del Art. 13 ROERC). Por tanto, salvo por lo que se refiere a estas dos cuestiones, en todo lo demás serán aplicables las normas nacionales, que cubren, en consecuencia, la mayor parte de los aspectos de la responsabilidad por daños y perjuicios (Art. 13.3. in fine ROERC).

2) Segunda, que esta norma sobre el régimen de responsabilidad aplicable se acompaña de una norma de conflicto de leyes que especifica qué ley se ha de aplicar a estos asuntos (Art. 13.3 ROERC), disposición que puede generar graves disfunciones en su aplicación, sobre todo para el acreedor.

3) Tercera y última, que lo dispuesto en este precepto sólo alcanza a la responsabilidad del acreedor con su deudor y no frente al banco ni a terceras personas (Art. 13.5 ROERC).

\section{El régimen general de responsabilidad del acreedor}

17. Esta regulación de mínimos, prevista en el Art. 13 del Reglamento, se formula en su primer apartado en los términos siguientes:

"El acreedor será responsable de cualquier daño o perjuicio que la orden de retención cause por su culpa al deudor. La carga de la prueba corresponderá al deudor".

Como puede verse, el Reglamento ha optado por prever un régimen de responsabilidad por culpa, que hace reposar en las espaldas del deudor todo el peso de la actividad probatoria precisa para acreditar los presupuestos de los que depende ("la carga de la prueba corresponderá al deudor").

18. Atendiendo al tenor del Art. 13 del Reglamento, esta responsabilidad nace de la concurrencia de los cuatro presupuestos que analizaremos en detalle a continuación:

$1^{\circ}$ Existencia de una orden de retención de cuentas, como marco en el que se producen los daños.

$2^{\circ}$ Demostración de un daño al deudor.

$3^{\circ}$ Acreditación de la culpa del acreedor.

$4^{\mathrm{o}}$ Acreditación del nexo causal.

\footnotetext{
${ }^{15}$ Véase sobre este punto el Estudio realizado por el Prof. Hess en 2004 sobre las retenciones de cuentas, en donde señala que, aunque la mayor parte de los países prevén para estos casos un sistema de responsabilidad objetiva (por ejemplo, en Alemania (Art. 717.2 ZPO), Bélgica (Art. 1398 CJ), Dinamarca (Art. 505), Holanda, Luxemburgo, España, Portugal (Art. 374.1 CPC)), hay Estados como Italia que mantienen la responsabilidad por culpa como Italia (Art. 96 CPC). Cfr. Study No. JAI/A3/2002/02 on making more efficient the enforcement of judicial decisions within the European Union: Transparency of a Debtor's Assets Attachment of Bank Accounts Provisional Enforcement and Protective Measures Version of 2/18/2004, nota 583 de la pág. 107. Puede consultarse en: http://www2.ipr.uni-heidelberg.de/studie/General\%20Report\%20Version\%20of\%2018\%20Feb\%202004.pdf.
} 


\section{Existencia de una orden de retención de cuentas}

19. La primera exigencia es, obviamente, que se haya dictado ya una orden de retención de cuentas de la que emana el daño o perjuicio irrogado al deudor ("que la retención cause") bien porque desde el principio la medida no debería haberse acordado por carecer de justificación, bien porque el acreedor no ha satisfecho todas las exigencias formales o procesales precisas para su perfección.

\section{Demostración de un daño al deudor}

20. El segundo presupuesto es la producción de un daño al deudor ${ }^{16}$. Tanto en el Art. 13.1 como en el Considerando $19^{\circ}$ del Reglamento se ha empleado la expresión "cualquier daño o perjuicio", que consideramos que debe interpretarse en el sentido de no dejar fuera ningún tipo de daño que se haya podido ocasionar al demandado. De hecho, durante la tramitación del Reglamento la delegación polaca quiso limitar esos daños a los derivados de la ejecución de la orden, petición que no prosperó, por lo que el texto definitivo incluye los daños derivados de la simple adopción de la medida cautelar ${ }^{17}$. Por supuesto, quedan comprendidos tanto todos los daños patrimoniales que hayan podido irrogarse al deudor como los posibles daños no económicos o inmateriales. Dentro de los primeros podrían citarse, por poner algunos ejemplos, los costes por haber tenido que hacer frente antes los tribunales a la orden de retención, el coste de la caución o de la garantía sustitutoria del Art. 38 ROERC, si la hubiere ofrecido para evitar el embargo de sus cuentas, o las pérdidas económicas que le hubiera supuesto su falta de liquidez o su falta de capacidad crediticia. No se nos escapa la dificultad que en muchos casos supone primero acreditar y luego medir en términos económicos el monto de estos daños ${ }^{18}$. Deben también entenderse incluidos los daños no patrimoniales que haya podido ocasionarle la medida, tales como, por ejemplo, los perjuicios que esta situación hayan podido ocasionarle a su reputación.

\section{Acreditación de la culpa ${ }^{19}$ del acreedor}

21. Pese a que varios Estados miembros mostraron su oposición a esta opción durante los debates legislativos del Reglamento ${ }^{20}$, finalmente se previó un sistema de responsabilidad únicamente basado en la culpa del acreedor. El texto guarda silencio sobre el significado y alcance de este término, que tiene lecturas muy variadas en los diversos ordenamientos nacionales. Algún autor ha entendido que ha de acudirse a los Derechos internos para suplir esta carencia ${ }^{21}$, si bien nos sumamos a la doctrina que apoya un concepto autónomo europeo de la culpa ${ }^{22}$, de amplio alcance, en el que se incluye tanto la actuación dolosa como la imprudente del acreedor ${ }^{23}$. En cualquier caso, son dos los comportamientos del acreedor de los que puede derivarse esta responsabilidad: a) primero, que haya instado una medida que no procedía cuando, por ejemplo, nunca existió peligro en la demora o si el riesgo alegado ya se había disipado o si el demandado ya había pagado la deuda o si el título ejecutivo en que basaba la orden estaba anulado (Art. 33.1.g ROERC); b) segundo, cuando, pese a estar justificada la medida, el acreedor

\footnotetext{
${ }^{16}$ En iguales términos se formula en las otras versiones: "damage" en la versión inglesa; "Schäden" en la alemana.

${ }^{17}$ Así, en la doctrina Rauscher, T. y Wiedemann, en Europäisches Zivilprozess und Kollisionsrecht, Art. 13, \#10 y HilbigLugani, K., en Münchener Kommentar, op.cit., Art. 13, \#4.

18 Así lo entiende también Trenker, M., en Schumacher, H., Köllensperger, B. y Trenker, M., Kommentar zur EUKontenpfändungsverordnung, Ed. Manz, Viena, 2017, p. 142.

${ }^{19}$ En otras versiones se emplean términos de significado análogo: "fault" en inglés, "faute" en francés o "Verschulden" en alemán.

${ }^{20}$ En concreto, señala TRENKER que se mostraron reacios a este régimen las delegaciones de Austria, Alemania y Francia (cfr. Trenker, M., en Schumacher, H., Köllensperger, B. y Trenker, M., Kommentar zur EU-Kontenpfändungsverordnung, op.cit., p. 144).

${ }^{21}$ Así Cuniberti, G., y Migliorini, S., The account preservation order..., op.cit., p. 170.

${ }^{22}$ Esta oportunidad de un concepto autónomo de culpa tuvo buen reflejo en el Asunto Brasserie du Pecheur SA/ Bundesrepublik Deutschhland (C-46/93, de 5 de marzo de 1996).

${ }^{23}$ Así, por ejemplo, Rauscher, T., Europäisches Zivilprozess..., op.cit., Art. 13, \#16, Trenker, M., en Schumacher, H., Köllensperger, B. y TRENKer, M., Kommentar zur EU-Kontenpfändungsverordnung, op.cit., p. 144.
} 
no hubiera satisfecho alguna de las obligaciones que le impone el Reglamento para la cumplimentación de la orden, tales como la aportación de ciertos documentos, o la obligación de notificación o si hubiere presentado una solicitud defectuosa.

Acreditación del nexo causal entre la conducta del acreedor y el daño producido al deudor por la existencia de la orden de retención de cuenta ${ }^{24}$

22. Por último, el deudor deberá acreditar la relación de causalidad entre los tres presupuestos anteriores para que pueda estimarse su solicitud: que, dictada una orden, su aplicación haya producido un daño cierto al deudor por una conducta que se le puede reprochar jurídicamente al acreedor. De hecho, como señala RAUSCHER, de los daños que "de todos modos" se hubieran producido no responde el acreedor ${ }^{25}$.

\section{Las presunciones de culpa}

23. Para facilitar la exacción de responsabilidad del acreedor, el legislador europeo decidió prever una "norma armonizada" -en términos del Considerando $19^{\circ}$ ROERC - con una lista de supuestos de presunción de culpabilidad que entran en juego cuando el acreedor hubiera incumplido ciertas obligaciones o hubiera omitido ciertas exigencias impuestas por el Reglamento ${ }^{26}$, presunciones que pueden rebatirse con prueba en contrario (presunción iuris tantum) ${ }^{27}$.

En concreto, el Art. 13.2 prevé los cuatro supuestos siguientes:

\section{$1^{\circ}$ Falta de incoación del procedimiento sobre el fondo del asunto.}

24. El Art. 10 ROERC impone al acreedor que solicita la orden la carga de iniciar el procedimiento sobre el fondo del asunto en un determinado plazo (que, por regla general, es de treinta días desde que presentó la solicitud de la orden), so pena de que la medida resulte revocada si no lo hace (Art. 10.2 ROERC) y además, si así lo pidiera el deudor, de tener que compensar económicamente al demandando por los posibles perjuicios producidos. Esta situación constituye el primer supuesto de presunción de culpa del Art. 13.2 ROERC. En todo caso, para que ésta opere se exige que se haya revocado la orden debido a la falta de incoación del procedimiento en plazo ${ }^{28}$. Con todo, hay dos supuestos excluidos de esta presunción: el primero, cuando no se hubiere iniciado el procedimiento porque el deudor pagó la deuda; y, el segundo, cuando las partes hubieren llegado a un acuerdo para poner fin al proceso ("otra forma de transacción entre las partes").

$2^{\circ}$ Incumplimiento por el acreedor de su obligación de "solicitar" la liberación de los importes retenidos en exceso con arreglo al artículo 27

25. Lo primero que cabe señalar es que la traducción española del apartado b) del Art. 13.2 es incorrecta ya que omite el término "solicitud", que se incluye en los otros idiomas en los que está traducido el Reglamento -véase, por ejemplo, en las redacciones en inglés ("has failed to request"), alemán (" $z u$ beantragen") o francés ("omis de demander")-. El texto, por tanto, debería ser del siguiente tenor: "si el

${ }^{24}$ En este sentido, sobre la necesidad de este nexo causal, Hilbig-Lugani, K., en Münchener Kommentar, op.cit., Art. 13, \#3, Rauscher, T., Europäisches Zivilprozess ..., op.cit., ART. 13,\#13.

${ }^{25}$ Cfr. RAuscher, T., Europäisches Zivilprozess..., op.cit., Art. 13,\#13.

${ }^{26}$ Incumplimiento que constituye el hecho base que ha de probar el deudor para que entren en juego estas presunciones legales. Véase en este sentido, Bernardo SAN José, A., La responsabilidad derivada de la adopción de medidas cautelares en el proceso civil, Ed. Tirant lo Blanch, 2018, p. 81.

${ }^{27}$ Aunque, como acertadamente apunta Bernardo SAn José, el Reglamento guarda silencio "sobre qué hechos o circunstancias podría proyectarse la prueba en contrario", por lo que habrán de ser los tribunales, señala esta autora, quienes deben terminar de confirmar su concurrencia (cfr. Bernardo SAN José, A., La responsabilidad derivada ..., op.cit., p. 82).

${ }^{28}$ Así lo entienden, entre otros, SenÉs Motilla, C., La orden europea de retención de cuentas, Ed. Aranzadi, 2015, p. 82. 
acreedor ha omitido la solicitud de liberar los importes retenidos en exceso con arreglo al Art. 27". Sin esta referencia, difícilmente encaja este precepto con lo dispuesto en el Art. 27 ROERC al que se remite, ya que la obligación que allí se impone al acreedor no es tanto la de liberar las cantidades retenidas en exceso sino justamente la de "solicitar" -así lo señala el título de dicho artículo-su liberación mediante la adopción de las "medidas necesarias" para ello ${ }^{29}$. De hecho, la competencia para efectuar dicha liberación de los fondos se atribuye al banco autorizado, en respuesta a la orden dada por la autoridad competente del Estado miembro de ejecución (Art. 27.2 ROERC). Recuérdese que el Art. 27 ROERC establece esta obligación una vez que ya se ha cumplimentado la orden cuando las cantidades embargadas excedan de la cantidad en dos supuestos: a) cuando "la orden afecte a varias cuentas en el mismo Estado o en Estados miembros diferentes"; o b) "cuando se haya dictado la orden después de haberse ejecutado una o varias órdenes nacionales equivalentes contra el mismo deudor para garantizar la misma deuda".

\section{$3^{\circ}$ Incumplimiento de las obligaciones previstas en el Art. 16 ROERC}

26. Este precepto impone a los solicitantes de las órdenes europeas de retención de cuentas las dos obligaciones siguientes: primera, que no pueda instar más de una solicitud ante más de un órgano jurisdiccional contra el mismo deudor para garantizar el mismo crédito (Art. 16.1 ROERC); segunda, que, al solicitar la orden, tienen que declarar necesariamente si ya habían solicitado previamente una "orden nacional equivalente" contra el mismo deudor y en referencia al mismo crédito (con o sin éxito, porque han de indicar también las que, en su caso hubieran sido rechazadas por inadmisible o infundadas) o, incluso, si ya la hubieran obtenido (Art. 16.2 ROERC) ${ }^{30}$. Pues bien, la presunción contemplada en este tercer apartado del Art. 13.2 ROERC juega cuando, además del incumplimiento de una de esas dos obligaciones del Art. 16 ROERC, una vez dictada la orden (esto es lo que parece significar el término "ulteriormente") ${ }^{31}$, se determine "su improcedencia o que sólo procedía por un importe inferior".

\section{$4^{\circ}$ Incumplimiento por parte del acreedor de sus obligaciones de notificación y traducción (Art. 13.2.d} ROERC)

27. Los Arts. 38 y 49 ROERC imponen al acreedor el deber de notificación y traducción de ciertos documentos y actuaciones, obligaciones cuyo incumplimiento puede dar lugar, incluso, a la revocación de la orden; igual fin tendría la medida si, impugnada la orden por este motivo y concedido un plazo para su subsanación, el acreedor hiciera caso omiso y no corrigiera el defecto apreciado (Art. 33 ROERC). Para estos casos opera también esta presunción de culpabilidad siempre que efectivamente ya se haya revocado la orden (por mor del Art. 33.1.b o c ROERC) o su ejecución se haya dejado sin efecto (por mor del Art. 34.1.iv ROERC) ${ }^{32}$.

28. Extraña a la doctrina que no se haya incluido un quinto apartado para dar cabida a los supuestos de responsabilidad del acreedor por haber omitido su obligación de declarar sobre la veracidad y exhaustividad de la solicitud, deber impuesto al acreedor en el Art. 8.2.o ROERC ${ }^{33}$. Como es bien sabido, en dicho apartado se prevé que el acreedor puede tener que responder con arreglo al Art. 13 por cualquier "alegación deliberadamente falsa o incompleta" que incluya en su solicitud inicial de la orden,

${ }^{29}$ Petición que ha de formalizarse mediante el formulario previsto en el Anexo V del Reglamento de Ejecución UE 2016/1823 de la Comisión, de 10 de octubre de 2016. Pese a que se impone esta obligación al acreedor, nada impide que, si así lo prevé el Derecho nacional, la liberación de estas cantidades retenidas en exceso pueda también iniciarse de oficio por las autoridad de ejecución competentes (Art. 27.3 ROERC).

${ }^{30}$ Con todo, esta obligación no impide que, en función del conjunto de las circunstancias del caso, el tribunal pueda llegar a acordar la orden europea de retención total o parcialmente incluso aunque el acreedor ya hubiera obtenido una medida nacional equivalente (Art. 16.4 ROERC).

${ }^{31}$ Así lo entiende Cuniberti, G., y Migliorini, S., The European Account..., op.cit., p. 171.

32 En estos casos SenÉs Motilla entiende que hay razones para sostener que esta declaración de responsabilidad puede ser un pronunciamiento más de la resolución por la que se decida el recurso (cfr. SenÉs Motilla, C., La orden europea ..., op.cit., pp. 84 y 85$)$.

${ }^{33}$ Así Rauscher, T., Europäisches Zivilprozess..., op.cit., ART. 13, \#19. 
por lo que hubiera sido deseable que se pudiera presumir su culpa en caso de que hubiera omitido esta información en su escrito.

\section{La aplicación subsidiaria de las legislaciones nacionales}

29. El apartado tercero del Artículo 13 ROERC se ocupa de dos cuestiones importantes y complementarias de lo previsto en los dos primeros apartados.

30. En primer lugar, prevé la aplicación subsidiaria del Derecho nacional de los Estados Miembros para todo lo no previsto expresamente en el Art. 13 ROERC; piénsese, por citar algunos ejemplos, en cuestiones tan relevantes como el alcance de la responsabilidad, la causalidad o las causas de justificación $^{34}$, sobre las que el Reglamente guarda silencio.

31. En segundo lugar, se permite a los Derechos nacionales complementar lo dispuesto en el Reglamento. El Artículo 13.3 ROERC establece que los Estados miembros podrán "mantener" o "introducir" en su Derecho nacional tanto motivos distintos de los previstos en el Reglamento ${ }^{35}$, tipos de responsabilidad ${ }^{36}$ más severos (como la responsabilidad objetiva, prevista como regla para estos supuestos en varios ordenamientos europeos ${ }^{37}$ ) así como normas diversas de carga de la prueba. Aunque poco más dice el Reglamento, la doctrina coincide en señalar que esta normativa interna siempre ha de ir "más allá de los estándares mínimos de responsabilidad" fijados a nivel europeo ${ }^{38}$, con respeto a los principios de "equivalencia y efectividad" y sin "frustar o complicar excesivamente el propósito del Reglamento" 39.

\section{La norma de conflicto de leyes}

32. Por último, era importante que el Reglamento se pronunciara sobre cuál debía ser el derecho aplicable a estas pretensiones indemnizatorias, cuestión de la que se ocupa la norma de conflicto de leyes prevista en el apartado cuarto del Artículo 13, que, como señala el Art. 48.f ROERC, deroga en este punto al Reglamento 864/2007 (conocido como Roma II). En concreto, contempla dos supuestos bien diversos en función del alcance de la medida cautelar.

33. El primero se refiere a los casos en los que la retención se lleva a cabo únicamente en un Estado miembro. El criterio aquí es el siguiente: la "ley aplicable a la responsabilidad del acreedor será la del Estado miembro de ejecución".

34. Más complejos son los supuestos de retención si las cuentas están en más de un Estado miembro. Cuando esto ocurre, resultan de aplicación varios ordenamientos ya que las órdenes han de ejecutarse en todos ellos, por lo que el legislador consideró oportuno dar una solución a este conflicto de leyes.

El Reglamento apuesta por dos criterios, que se aplican de forma subsidiaria. El primero atiende al lugar de residencia habitual del deudor, definida ésta conforme al artículo 23 del Reglamento (CE)

\footnotetext{
${ }^{34}$ Ejemplos a los que se refiere Hilbig-Lugani, K., en Münchener Kommentar, op.cit., comentario al Art. 13, párrafo 8.

${ }^{35}$ Cabe entender que, con la alusión a los "motivos" se refiere a supuestos de responsabilidad derivados de la medida cautelar, tales como los previstos en el apartado segundo del Art. 13. Así, por ejemplo, lo entiende también ANTón JuAREZ, I., Litigación Internacional en la Unión Europea III. La orden europea de retención de cuentas, Ed. Aranzadi, 2018, p. 76.

${ }^{36}$ Como señala BeRnARdo SAN José, con la expresión "tipos de responsabilidad" parece que el Reglamento se refiere a "criterios de imputación subjetiva o factores de atribución”, tales como la responsabilidad objetiva, que el Reglamento cita como ejemplo en su Considerando $19^{\circ}$ (cfr. Bernardo SAn José, A., La responsabilidad derivada..., op. cit., p. 85).

${ }^{37}$ Entre otros, Alemania: \#945 ZPO; Austria: \#394 EO; España: Arts. 742 y 745 LEC, en unión con la jurisprudencia mayoritaria (por todas, STS núm. 584/2015, de 29 de octubre).

${ }^{38}$ Cfr. Cuniberti,G., y Migliorini, S., The European Account..., op.cit., p. 172.

${ }^{39}$ Cfr. Hilbig-Lugani, K., Münchener Kommentar, op.cit., Comentario al Art. 13 REOC \#8.
} 
$\mathrm{n}^{\circ} 864 / 2007$, de 11 de julio, del Parlamento Europeo y del Consejo, relativo a la ley aplicable a las obligaciones extracontractuales (conocido como Roma II). En este artículo se precisa que, cuando se trata de sociedades, asociaciones o personas jurídicas, la residencia será el lugar de su administración central ${ }^{40}$, mientras que, cuando se refiera a una persona física "que esté ejerciendo su actividad profesional, será el establecimiento principal de dicha persona". Se omite, sin embargo, toda referencia a las personas físicas cuando no estén ejerciendo actividad.

En segundo lugar, en defecto de este primer criterio - esto es, en caso de que "el deudor no residiere en ningún Estado miembro de ejecución" (o si éste no se hubiere podido determinar)-, se prevé la aplicación de la ley del Estado de ejecución "con el que el asunto tenga la conexión más estrecha", expresión imprecisa, que puede dar lugar a más de un problema en su aplicación. El Reglamento apunta a la cuantía del importe retenido en los distintos Estados miembros de ejecución como ejemplo de uno de los factores que el órgano jurisdiccional puede tener en cuenta para fijar esta conexión más estrecha (Considerando $19^{\circ}$, tercer párrafo). Podrían añadirse a éste los siguientes criterios que señala HiLBIGLUGANI: un lugar en donde se sepa que reside el deudor, aunque no sea su residencia habitual, la nacionalidad de las partes o el lugar donde se firmó el contrato o donde éste deba cumplirse ${ }^{41}$.

El juego de estas normas de conflicto produce consecuencias de no poca importancia en la actitud de las partes frente a estos procedimientos. En primer lugar, como señala DoMEJ, el acreedor va a tener una importante sensación de inseguridad dada la dificultad que se va a encontrar con mucha frecuencia a la hora calcular el riesgo al que se expone al pedir la medida a sabiendas de que, en caso de que finalmente tenga que compensar al deudor, se aplicará derecho extranjero para determinar su responsabilidad; de hecho, este autor recomienda a los acreedores que pidan asesoramiento jurídico en el/los Estado/s en donde el deudor tenga sus cuentas para saber cómo es de severo en ese país el régimen de responsabilidad al que se expone. Por otro lado, teniendo en cuenta estas normas, el deudor puede decidir fijar sus cuentas en el Estado que prevea un régimen de responsabilidad más exigente y, por tanto, más conveniente para él en el caso de una futura reclamación de este tipo ${ }^{42}$.

\section{La competencia para conocer de estos asuntos}

35. Dado que, salvo por lo que se refiere al Art. 13.4 ROERC, el Reglamento señala que puede ser de aplicación el Reglamento 864/2007 sobre obligaciones extracontractuales (Art. 48.f ROERC), ha de entenderse que la competencia para conocer de estos asuntos puede venir determinada por la aplicación del fuero especial del segundo apartado del Art. 7 del Reglamento 1215/2012, de 12 de diciembre de 2012 (conocido como Bruselas Ibis), como fuero de ataque frente al general de los Arts. 4 y 5. Este fuero especial atribuye la competencia al "órgano jurisdiccional del lugar donde se haya producido o pueda producirse el hecho dañoso" ${ }^{43}$ que, en este caso, sería el del lugar en donde la/s cuenta/s se hallen y se vayan a embargar. Por tanto, en estos supuestos de responsabilidad por daños derivados de la orden de retención de cuentas el demandante podrá elegir entre este foro o el general del domicilio del demandado, según mejor le convenga.

\section{Consideraciones finales}

36. Tras el examen detallado de las normas armonizadas sobre responsabilidad del acreedor, cabe extraer dos conclusiones fundamentales.

\footnotetext{
${ }^{40}$ Norma complementada para el caso de sucursales con la siguiente: "Cuando el hecho generador del daño o el daño se produzca en el curso de las operaciones de una sucursal, agencia o cualquier otro establecimiento, se considerará residencia habitual el lugar en el que dicha sucursal, agencia u otro establecimiento está situado".

${ }^{41}$ Cfr. Hilbig-Lugani, K., en Münchener Kommentar, op.cit., Art. 13, \#13.

${ }^{42}$ Cfr. DomeJ, T., "Europäisches vorläufige Kontenpfändung: der erste Schritt einer langen Reise", GPR, 2017, p. 93.

43 Así también lo entienden Hilbig-Lugani, K., en Münchener Kommentar, op.cit., Art. 13, \#9.
} 
37. La primera, en referencia a la posición del deudor. Consideramos que el régimen de los Arts. 12 y 13 del Reglamento, unidas a las normas sobre impugnación de la orden y de su ejecución previstas en los Arts. 33 y siguientes, ofrecen al deudor mecanismos adecuados y suficientes de reacción y de protección frente a posibles abusos de los acreedores que insten órdenes de retención de sus cuentas sin razón bastante. El deudor puede impugnar la decisión sobre la no prestación de caución si considera que ésta debería haberse acordado o si se acordó pero por un importe que considera bajo y, cuando quiera exigir responsabilidades por daños y perjuicios al acreedor, tiene garantizada una protección mínima de acuerdo con el régimen del art. 13, que con frecuencia se encuentra reforzada por las normas nacionales. Además, la norma de conflicto le permite conocer de forma anticipada qué norma material se va a aplicar en el proceso por daños y perjuicios.

38. La segunda, en relación a la posición del acreedor. Bien es cierto que en una primera aproximación es fácil afirmar que el Reglamento apuesta por favorecer la posición del acreedor que solicita una orden de retención de cuentas ya que, si consigue demostrar que la medida está justificada, ésta se adopta sin dar audiencia al deudor. Pero, a la vista del contenido de los Arts. 12 y 13 del Reglamento, consideramos que el acreedor no ocupa una posición tan privilegiada como aparenta. A nuestro entender, dos notas caracterizan su situación: inseguridad y complejidad. La opción del Reglamento por una responsabilidad de mínimos obliga a los tribunales ante los que se presente la solicitud de indemnización por daños y perjuicios a aplicar en múltiples cuestiones las normas nacionales del Estado de ejecución, que en muchos casos será Derecho extranjero para el tribunal que tenga que resolver la acción por daños y casi siempre también para el acreedor, puesto que generalmente la competencia se atribuirá al tribunal del lugar en donde el deudor tiene la cuenta, lo que obliga al acreedor a litigar en un Estado extranjero. Recuérdese que a esto se suma el juego de la norma de conflicto del Art. 13.4 ROERC, que conduce con frecuencia a la aplicación de unas normas sobre responsabilidad más severas, ya que, como señalamos, da pie incluso a que el deudor elija colocar sus fondos en el Estado en el que sabe que puede obtener mejor compensación económica por daños. Esta complejidad se traslada al momento de la decisión sobre la caución, puesto que el tribunal de origen (en general, el que sea competente para conocer del fondo del asunto, de acuerdo con el art. 6 ROERC) va a tener que fijar su cuantía con arreglo a todas estas consideraciones del Art. 13 ROERC (aplicando así derecho que le es ajeno) en función de la indemnización que le podría llegar a corresponder al deudor si se llegara a sufrir algún daño como deriva del procedimiento cautelar. Y, es más, pese a la dificultad de esta tarea para el juez y la incertidumbre para el acreedor, el Reglamento no ha puesto en manos de este último un mecanismo de impugnación para estos casos, y, aunque es cierto que en ocasiones podrá acudir a los recursos previstos en el Derecho nacional, estos pueden no existir o ser insuficientes, lo que conllevaría la denegación del acceso a la medida cautelar de forma arbitraria o injustificada sin que nada pudiera hacer el acreedor para evitarlo.

39. En suma, consideramos que sería oportuno introducir normas armonizadas más completas en la previsión del régimen de responsabilidad del acreedor, reforzando el contenido del Art. 13 ROERC, para poder realmente conseguir el equilibrio deseado por el legislador europeo entre acreedores y deudores. 